\title{
Osimertinib and Ramucirumab Induced Pyogenic Granulomas: A Possible Synergistic Effect of Dual Oncologic Therapy
}

Robert P. Daze ${ }^{1}$, Jewell Dinkins ${ }^{2}$, Matthew H. Mahoney ${ }^{3}$

1. Dermatology, Largo Medical Center, Largo, USA 2. Dermatology, Meharry Medical College, Nashville, USA 3. Dermatology, Mahoney Dermatology, Pinellas Park, USA

Corresponding author: Robert P. Daze, rdaze022@marian.edu

\begin{abstract}
Pyogenic granulomas represent benign vascular tumors that can present on the skin and mucous membranes. Multiple etiologic agents have been implicated in the pathogenesis including several systemic medications. Two notable oncologic therapies, epidermal growth factor receptor inhibitors and vascular endothelial growth factor receptor inhibitors, have each been associated with drug-induced pyogenic granulomas. We report a novel case report of dual therapy, medication-induced pyogenic granulomas. This likely represents a synergistic relationship between an epidermal growth factor receptor inhibitor, osimertinib, and a vascular endothelial growth factor receptor inhibitor, ramucirumab.
\end{abstract}

Categories: Dermatology, Pathology, Oncology

Keywords: pyogenic granuloma, egfr, vegf, osimertinib, ramucirumab

\section{Introduction}

Pyogenic granulomas, or lobular capillary hemangiomas, are benign vascular proliferations of the skin and mucous membranes. Grossly, these lesions present as polypoid papules and nodules with a propensity to ulcerate. Although multiple causative agents have been implicated in the pathogenesis, various systemic medications are known triggers for this vascular anomaly [1,2]. Notably, pyogenic granulomas occur in $10 \%$ to $30 \%$ of cases where epidermal growth factor receptor inhibitors are used for the treatment of advanced malignant tumors [1]. More recently identified in the literature, vascular endothelial growth factor receptor inhibitors present as a paradoxical etiology in the development of pyogenic granulomas. Our clinical observation identified a novel and likely synergistic interaction between an epidermal growth factor receptor inhibitor, osimertinib, and a vascular endothelial growth factor receptor inhibitor, ramucirumab.

Review began 05/07/2021 Review ended 05/16/2021 Published 05/17/2021

\section{(๑) Copyright 2021}

Daze et al. This is an open access article distributed under the terms of the Creative Commons Attribution License CC-BY 4.0., which permits unrestricted use, distribution, and reproduction in any medium, provided the original author and source are credited.

\section{Case Presentation}

A 68-year-old Caucasian female with a history of stage IV non-small cell lung cancer and notable epidermal growth factor receptor exon 19 mutations presented with a new tender bright red nodule present on the left buttock, with onset approximately three months prior to presentation. The patient endorsed rapid growth and intermittent bleeding but denied any previous trauma to the area. The patient had a similar lesion present on her right upper chest. Since her lung cancer diagnosis in April 2020, the patient has been successfully treated with combination therapy of osimertinib, a third-generation epidermal growth factor receptor inhibitor, and ramucirumab, a vascular endothelial growth factor receptor inhibitor. Physical examination demonstrated a solitary, friable, red exophytic nodule located on the left superomedial buttock at the gluteal cleft and measuring $1.6 \times 1.0 \times 0.7 \mathrm{~cm}$ (Figure 1). A similar lesion was present on the right upper chest measuring $0.6 \times 0.5 \mathrm{~cm}$. Shave biopsies were obtained from both sites and were evaluated by hematoxylin-eosin staining. Each specimen demonstrated an exophytic lesion with a proliferation of small capillaries in a lobular pattern separated by fibrous septae. These histopathological findings in both shave biopsies were consistent with pyogenic granulomas (Figures 2, 3). After shave removal the area was treated with a curettage and electrofulguration, with no subsequent clinical recurrence. Given the clinicopathologic setting, we believe these tumors very likely occurred secondary to the patient's current oncologic therapy; both medications are known etiologic agents in the formation of pyogenic granulomas. 


\section{Cureus}

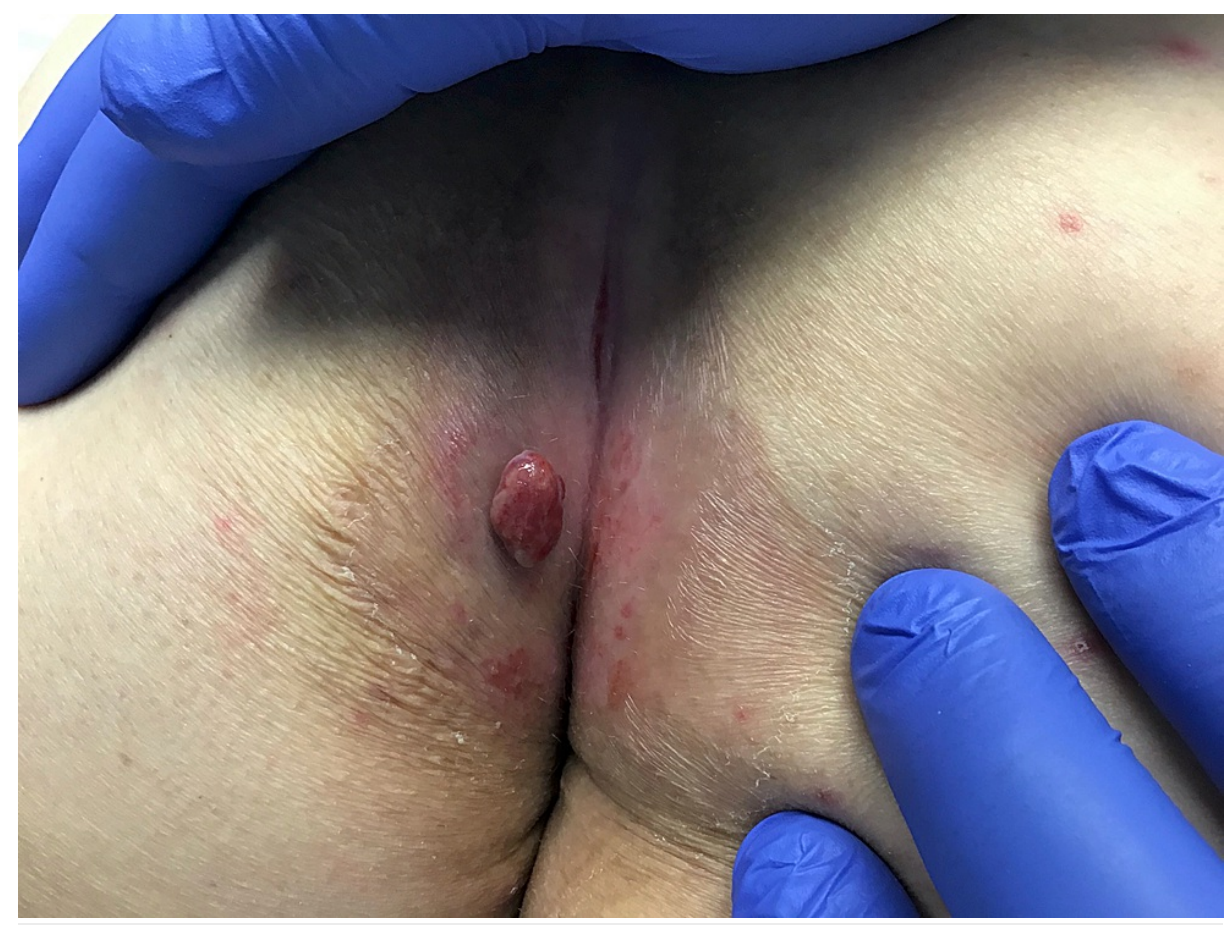

FIGURE 1: Solitary, friable, red polypoid nodule present on the left medial buttock.

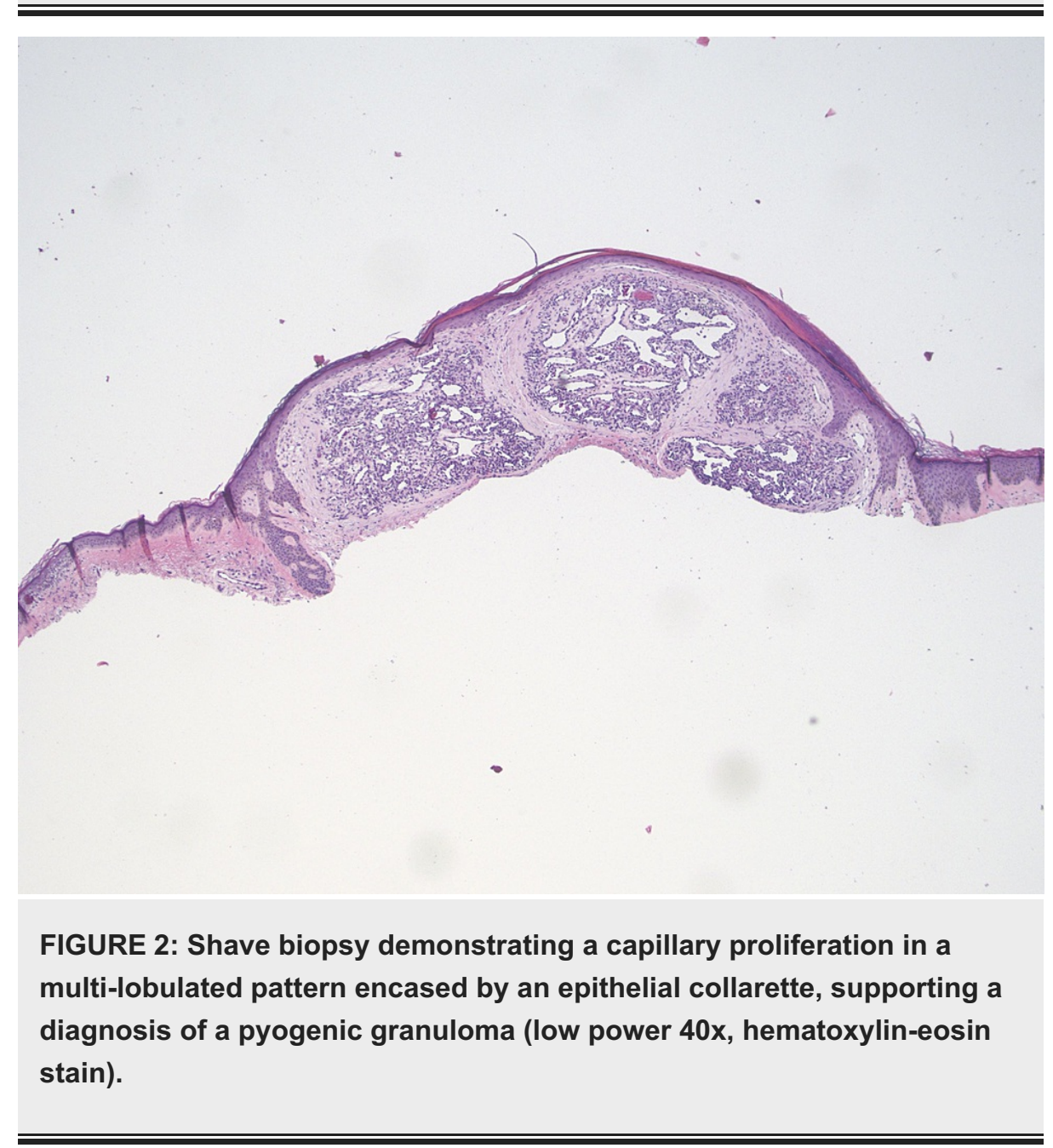




\section{Cureus}

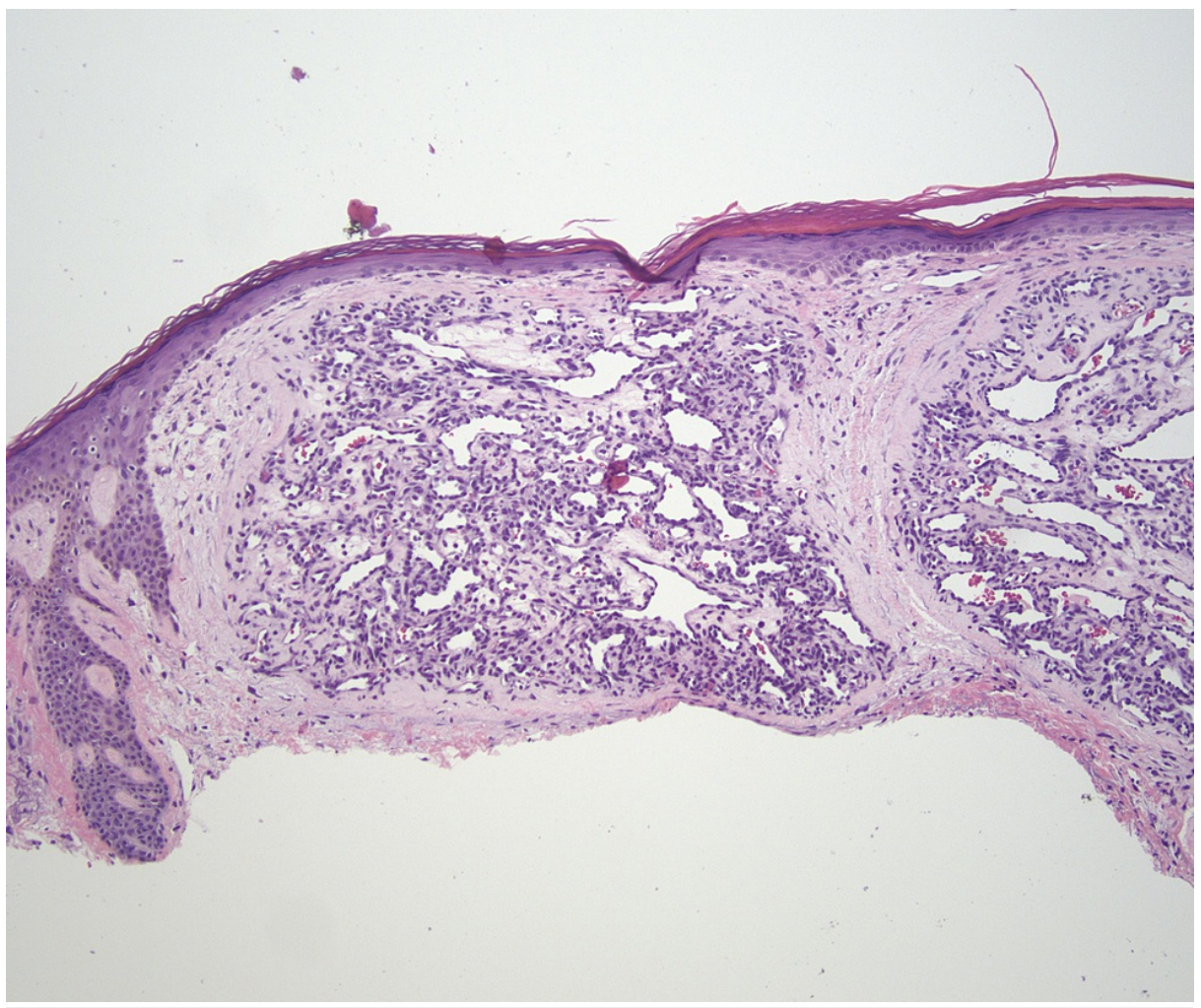

\section{FIGURE 3: Shave biopsy demonstrating a capillary proliferation in a multi-lobulated pattern encased by an epithelial collarette, supporting a diagnosis of a pyogenic granuloma (medium power 100x, hematoxylin- eosin stain).}

\section{Discussion}

Pyogenic granulomas, also known as lobular capillary hemangiomas, are benign vascular tumors that can affect the skin and mucosal membranes. Multiple causative agents have been implicated in the pathogenesis including chronic irritation, prior trauma, hormones, and systemic medications such as retinoids, indinavir, and epidermal growth factor receptor inhibitors [2]. We report a case of eruptive pyogenic granulomas as a proposed synergistic effect of two systemic medications known to cause these vascular tumors: epidermal growth factor receptor inhibitors and vascular endothelial growth factor receptor inhibitors [3,4]. To our knowledge this is the first documented case in the literature highlighting the combined synergy between these two oncologic medications.

Epidermal growth factor receptors affect cellular differentiation and proliferation. Dysregulation or overexpression of this receptor can lead to tumor-induced angiogenesis [5]. Osimertinib is a thirdgeneration kinase inhibitor of the epidermal growth factor receptors. It binds irreversibly to certain mutant forms of epidermal growth factor receptors likely minimizing the cutaneous and gastrointestinal adverse events of its predecessors. This selective inhibition likely diminishes but does not fully negate the potential for adverse toxicities [2]. As a medication class, epidermal growth factor receptor inhibitors are associated with a wide spectrum of dermatologic toxicities including an early onset papulopustular or acneiform eruption, xerosis, pruritus, and photosensitivity [5]. Epidermal growth factor receptor inhibitor therapy is also associated with paronychia, which may lead to the development of pyogenic granuloma like lesions $[5,6]$. These lesions typically occur $4-8$ weeks after treatment but can be a late manifestation seen up to six months later as seen in our patient.

Ramucirumab is a fully human immunoglobulin G1 (IgG1) monoclonal antibody that targets the extracellular domain of vascular endothelial growth factor receptor 2 , blocking the binding site for various vascular endothelial growth factor-related ligands. The most common adverse events with the systemic infusion are non-dermatologic including hypertension, peripheral edema, hypoalbuminemia, thrombocytopenia, and fatigue $[3,7]$. Vascular tumors are not a well-known complication of vascular endothelial growth factor therapy as angiogenesis is suppressed. In the phase I clinical trial of CDP791, a vascular endothelial growth factor receptor- 2 inhibitor, seven out of 31 patients developed benign hemangiomas after three cycles of therapy [8]. Lim et al. described the growth of a vascular tumor, resembling a tufted angioma, during ramucirumab treatment [7]. This particular tumor harbored a single somatic mutation in the knockdown 
resistance gene which encodes for vascular endothelial growth factor-2, likely conferring an aberrant mechanism to vascular tumorigenesis. Testing for this particular mutation was not performed in our case. This paradoxical angiogenic event during ramucirumab therapy was noted in subsequent case reports, albeit with other combined oncologic therapies such as paclitaxel and docetaxel $[4,7,9,10]$. The timing of the tumor onset ranged from approximately two weeks to six months after administration with multiple sites affected including the mucosa, nail apparatus, trunk, and extremities $[4,7,9,10]$. While vascular endothelial growth factor inhibition is thought to downregulate the tumoral angiogenesis, the mechanism behind this paradoxical reaction remains largely undefined.

\section{Conclusions}

In conclusion, we report a case of pyogenic granulomas arising in the setting of epidermal growth factor receptor and vascular endothelial growth factor receptor inhibition. While other combined therapies have been documented in the literature, to our knowledge this is the first case of pyogenic granulomas arising during this specific concomitant therapy. While individually each medication is implicated as a causative agent, we propose this combined therapy to be a manifestation of a synergistic effect on vascular endothelial cell proliferation. While further studies are necessary to delineate this mechanistic interaction, it behooves physicians to recognize this novel adverse event and monitor for the development of vascular tumors.

\section{Additional Information}

\section{Disclosures}

Human subjects: All authors have confirmed that this study did not involve human participants or tissue. Conflicts of interest: In compliance with the ICMJE uniform disclosure form, all authors declare the following: Payment/services info: All authors have declared that no financial support was received from any organization for the submitted work. Financial relationships: All authors have declared that they have no financial relationships at present or within the previous three years with any organizations that might have an interest in the submitted work. Other relationships: All authors have declared that there are no other relationships or activities that could appear to have influenced the submitted work.

\section{References}

1. Cubiró X, Planas-Ciudad S, Garcia-Muret MP, Puig L: Topical timolol for paronychia and pseudopyogenic granuloma in patients treated with epidermal growth factor receptor inhibitors and capecitabine. JAMA Dermatol. 2018, 154:99-100. 10.1001/jamadermatol.2017.4120

2. Wollina U: Systemic drug-induced chronic paronychia and periungual pyogenic granuloma . Indian Dermatol Online J. 2018, 9:293-8. 10.4103/idoj.IDOJ_133_18

3. Lim YH, Odell ID, Ko CJ, Choate KA: Somatic p.T771R KDR (VEGFR2) mutation arising in a sporadic angioma during ramucirumab therapy. JAMA Dermatol. 2015, 151:1240-3. 10.1001/jamadermatol.2015.1925

4. Ibe T, Hamamoto Y, Takabatake M, Kamoshida S: Development of pyogenic granuloma with strong vascular endothelial growth factor receptor-2 expression during ramucirumab treatment. BMJ Case Rep. 2019, 12:e231464. 10.1136/bcr-2019-231464

5. Abdullah SE, Haigentz M Jr, Piperdi B: Dermatologic toxicities from monoclonal antibodies and tyrosine kinase inhibitors against EGFR: pathophysiology and management. Chemother Res Pract. 2012, 2012:351210. 10.1155/2012/351210

6. Balagula Y, Garbe C, Myskowski PL, Hauschild A, Rapoport BL, Boers-Doets CB, Lacouture ME: Clinical presentation and management of dermatological toxicities of epidermal growth factor receptor inhibitors. Int J Dermatol. 2011, 50:129-46. 10.1111/j.1365-4632.2010.04791.x

7. Kosumi H, Nishie W, Sugai T, et al.: Ramucirumab-induced multiple haemangiomas of the skin: two case reports. Acta Derm Venereol. 2018, 98:454-5. 10.2340/00015555-2869

8. Ton NC, Parker GJ, Jackson A, et al.: Phase I evaluation of CDP791, a PEGylated di-Fab' conjugate that binds vascular endothelial growth factor receptor 2. Clin Cancer Res. 2007, 13:7113-8. 10.1158/1078-0432.CCR-071550

9. Espinosa Lara P, Medina-Puente C, Riquelme Oliveira A, Jiménez-Reyes J: Eruptive cherry angiomas developing in a patient treated with ramucirumab. Acta Oncol. 2018, 57:709-11. 10.1080/0284186X.2017.1410287

10. Watanabe R, Nakano E, Kawazoe A, et al.: Four cases of paradoxical cephalocervical pyogenic granuloma during treatment with paclitaxel and ramucirumab. J Dermatol. 2019, 46:e178-80. 10.1111/1346-8138.14693 